\title{
A new investigation of the acoustic imaging with nematic liquid crystals $\left({ }^{*}\right)(* *)$
}

\author{
J. N. Perbet, M. Hareng and S. Le Berre \\ THOMSON-CSF, Laboratoire Central de Recherches, \\ Domaine de Corbeville, B.P. 10, 91401 Orsay, France \\ (Reçu le 21 septembre 1978, révisé le 13 décembre 1978, accepté le 22 décembre 1978)
}

\begin{abstract}
Résumé. - Nous avons étudié la biréfringence induite par les ultrasons dans une cellule à cristal liquide nématique en vue d'évaluer les performances d'une rétine sonosensible. Les temps de réponse et la sensibilité ont été améliorés en appliquant continûment un champ électrique sur la cellule. De plus, l'introduction d'une grille dans l'épaisseur de cristal liquide améliore la résolution. D'un point de vue plus fondamental, différents mécanismes apparaissent simultanément et ne peuvent être tous expliqués par les modèles existants.
\end{abstract}

\begin{abstract}
Acoustically induced birefringence has been studied in homeotropic cell of nematic liquid crystal in order to obtain an acoustic image detector. The response times and the sensitivity were improved with an electric field always applied on the liquid crystal cell. The improvement of the resolution was obtained by introducing a grid in the cell which divides the sample into a matrix of small liquid crystal cells acting as individual detectors. About the mechanisms, different phenomena occur at the same time, one of them being a mechanism which is not explained within the framework of previous models.
\end{abstract}

1. Introduction. - Ultrasonic induced birefringence has been studied by many investigators in the hope of setting up a liquid crystal detector that could convert real time acoustic energy into a bidimensional optical pattern.

The aim of this study was to improve the characteristics of an ultrasonic detector using a liquid crystal cell. First, we describe the experimental set up used, and we report observations and measurements on the optical pattern shown by the cell. Then we present the improvement of the response time, the sensitivity and the resolution for display applications. On the other hand various models have been proposed to explain the interaction of ultrasounds with a nematic liquid crystal, but most of them lead to very different results $[1-7]$ : hence we have examined the various mechanisms involved in this interaction.

2. Experiment. - We have measured the birefringence induced in a liquid crystal cell, composed of a thin film of homeotropically aligned nematic liquid crystal sandwiched between two glass plates. This cell was imersed in a water bath in front of a

${ }^{*}$ ) Work supported by D.R.E.T. Contract $76 / 34 / 458$.

$\left({ }^{* *}\right)$ Work presented at the $" 7$ e Congrès International sur les Cristaux Liquides », Bordeaux, 1978. piezoelectric transducer driven from $0.9 \mathrm{MHz}$ to 3.6 $\mathrm{MHz}$. For birefringence measurements the cell was placed between crossed polarizers and illuminated with a monochromatic light beam falling at normal incidence.

As shown on figure 1 the birefringence of the cell can be measured either in transmission or in reflection. The distance $d$ from the transducer to the cell is much larger than the Fresnel zone boundary (i.e. $d \geqslant a^{2} / \Lambda$, where : $\Lambda$ is the ultrasonic wavelength, and a the transducer diameter), and the ultrasonic beam diameter is smaller than the cell dimensions.

We measure the incident acoustic intensity with a torque pendulum placed close to the front plate of the liquid crystal cell. This is the relevant parameter for

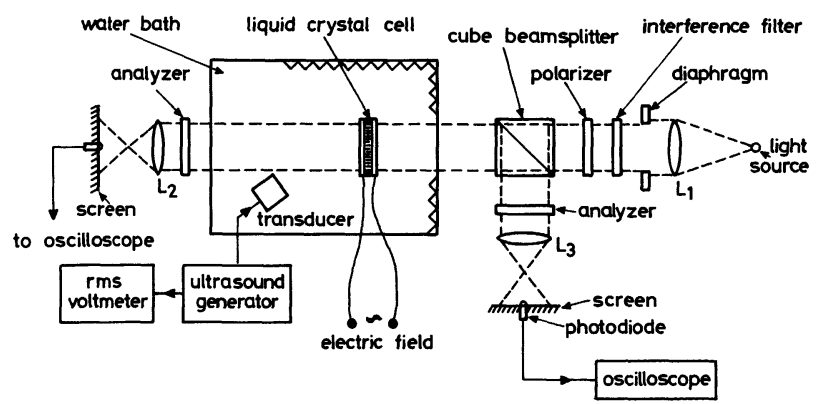

Fig. 1. - Experimental setup. 
RELATIVE ACOUSTIC
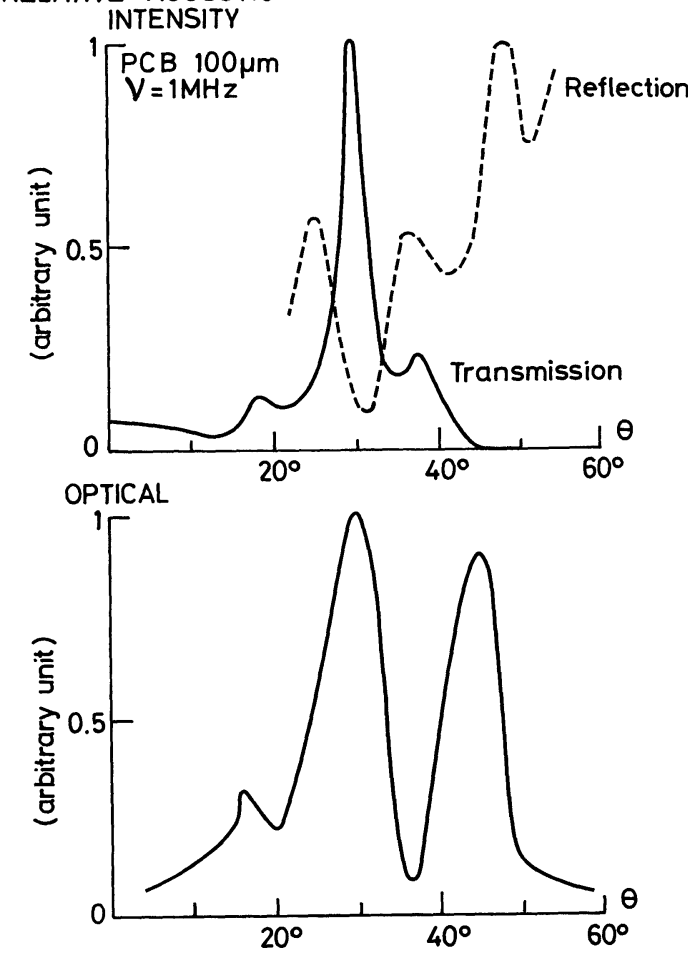

U.S. BEAM INCIDENT ANGLE

Fig. 2. - a) Acoustic transmission and reflection of the liquid crystal cell versus the incidence angle. $b$ ) Angular dependence of the sensitivity of the cell.
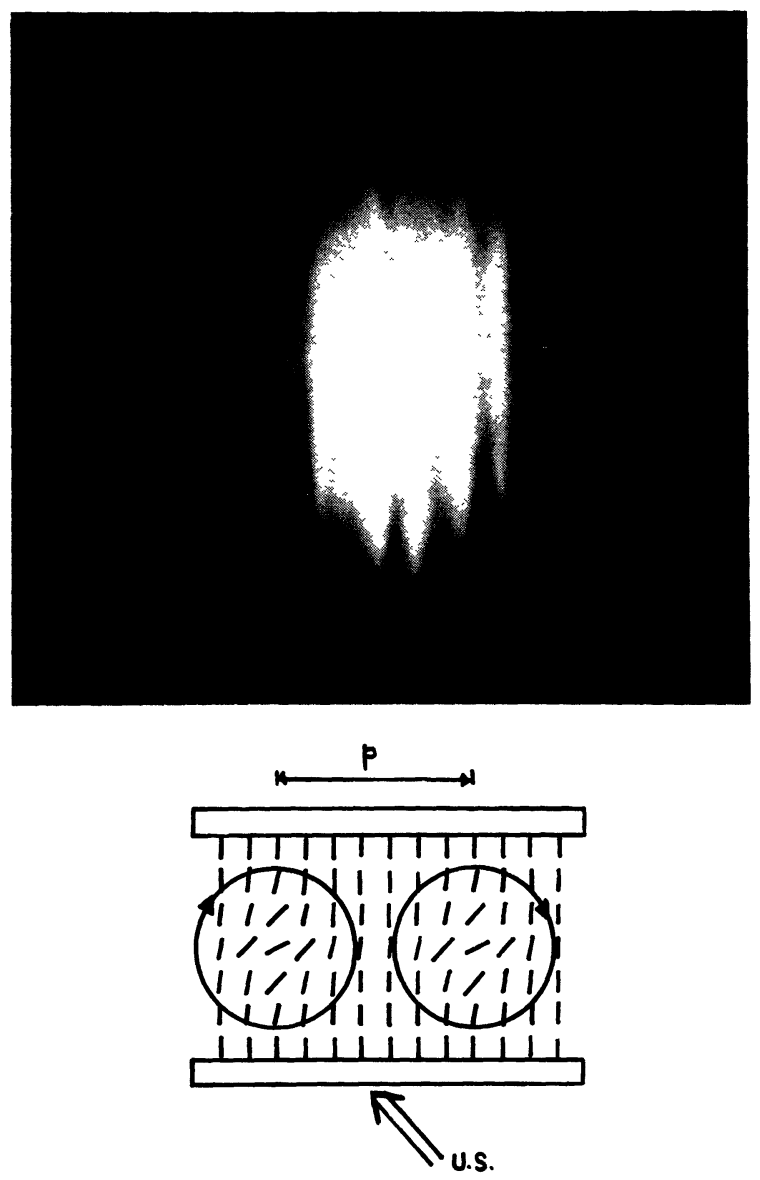

a)

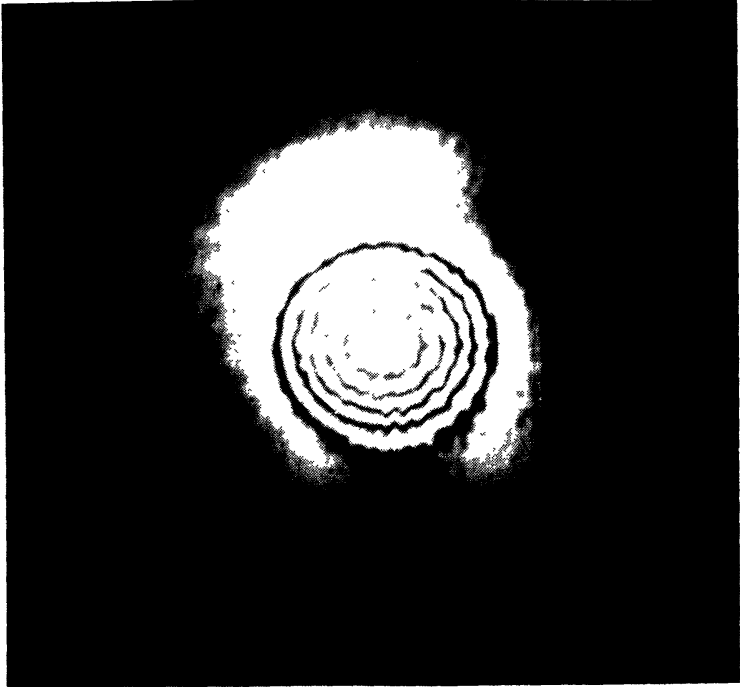

b)
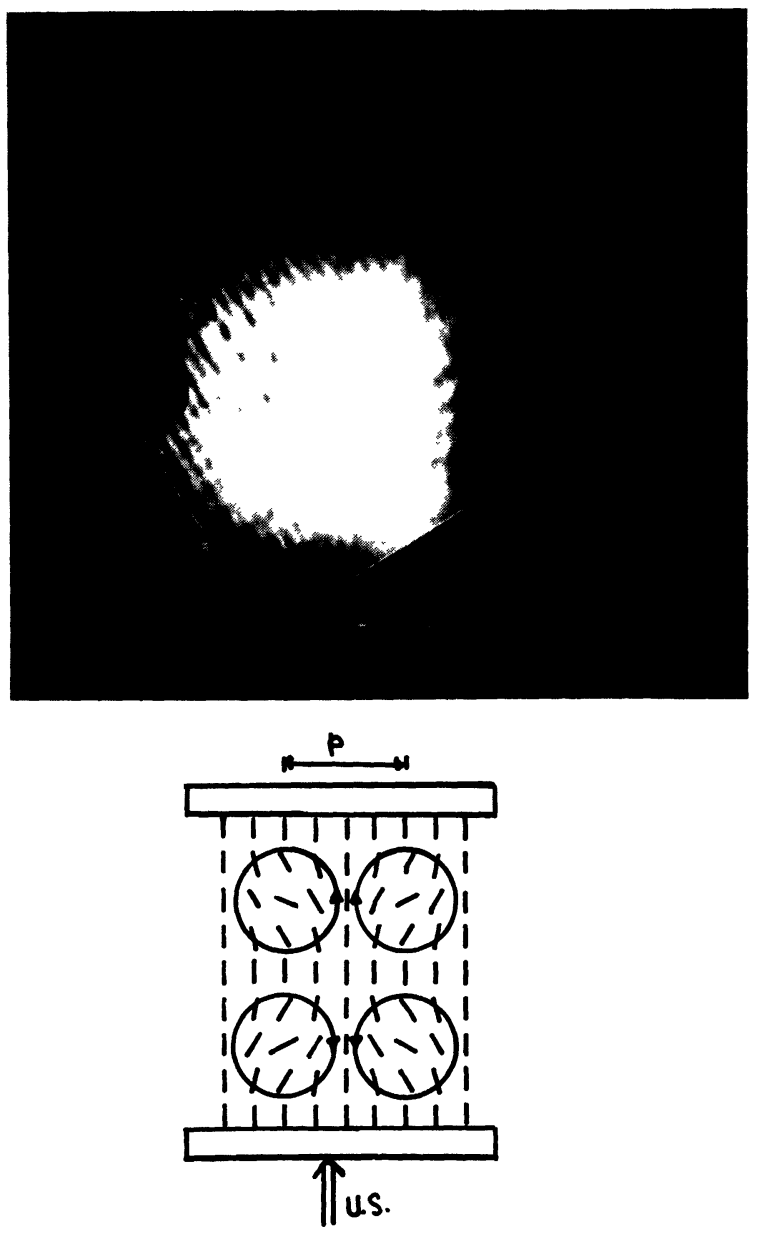

c)

Fig. 3. - Optical pattern with an acoustic beam at $1.8 \mathrm{MHz}$, incidence angle $(\theta) 30^{\circ}$, and distance from the transducer to the cell $30 \mathrm{~cm}$. a) Fringes normal to the incident plane

$$
\left(P_{\text {u.s. }}=10 \mathrm{~mW} / \mathrm{cm}^{2}\right)
$$

and the director orientation in the cell thickness (after Miyano and Shen [4]). b) Radial symmetry fringes $\left(P_{\text {u.s. }}=30 \mathrm{~mW} / \mathrm{cm}^{2}\right) . c$ ) Boundary effects $\left(P_{\text {u.s. }}=10 \mathrm{~mW} / \mathrm{cm}^{2}\right)$ and the director orientation in the cell thickness (after Sripaipan et al. [7]). 
technical purposes, and as a consequence, we do not know the real acoustic intensity inside the liquid crystal. The acoustic incident angle $\theta$ can vary from $0^{\circ}$ to $60^{\circ}$; the angular dependence of the ultrasonic transmission and reflection of the liquid crystal cell are measured within the same range, with a second piezoelectric transducer used as a receiver.

The liquid crystal cell is built with two glass plates, $5 \times 5 \mathrm{~cm}^{2}$ with different thicknesses varying from $0.1 \mathrm{~mm}$ to $2.5 \mathrm{~mm}$. When we want to apply an electric field, these glass plates are coated either with two transparent electrodes for transmission measurements or with a transparent electrode and a metallic one for reflection measurements. The liquid crystal thickness varies from $30 \mu \mathrm{m}$ to $500 \mu \mathrm{m}$.

All these measurements are performed at room temperature, with two nematic compounds : ZLI 518 (Merck) and pentyl-cyanobiphenyl (P.C.B.).

3. Experimental results. - The optical pattern has been investigated for different cells submitted to ultrasonic waves.

The sensitivity of these cells depends strongly on the acoustic incident angle $\theta$, but without significant change of the optical pattern. Whatever the thicknesses of the glass plates $(0.1 \mathrm{~mm}$ to $2.5 \mathrm{~mm})$ and the thickness of the liquid crystal $(30 \mu \mathrm{m}$ to $500 \mu \mathrm{m})$ may be, we observe this type of angular dependence. These angular dependences of the sensitivity are mainly related to the cell structure and not to the liquid crystal ; indeed we observe that the increase of sensitivity corresponds to a good acoustic transmission or reflection of the cells (e.g. Fig. 2). All the following results are given for angles $\theta$ which correspond to a good sensitivity.

3.1 Optical PatTern. - The spatial distribution of the optical signal shows two main characteristics :

a) Vertical fringes (cf. Fig. 3a) (i.e. normal to the u.s. incident plane). Their periodicity is frequency dependent but there is not a simple relation between the u.s. frequency and the periodicity. We also notice a slight influence of the incident angle $\theta$. Whatever the thicknesses of the glass plates may be, we always observe these striations. Miyano and Shen's mechanism could qualitatively explain this feature [4].

b) Radial symmetry fringes (Fig. $3 b$ ). They appear for higher ultrasonic intensity, and they spread out in the whole cell as the intensity increases. This phenomena will be described in the next paragraph.

When the u.s. beam falls close to an edge of the cell, we observe a third system of fringes parallel to the boundaries (cf. Fig. 3c), which can be explained by Sripaipan et al's mechanism [7].

3.2 RADIAL SYMMETRY FRINGES. - This predominant phenomena has been investigated as a function of the ultrasonic intensity and frequency.
As the acoustic intensity increases, we observe the vertical fringes described previously, and dark concentric rings moving outward.

Figure IV represents the variation of the optical signal at the centre of the irradiated area, the maxima and minima of this signal correspond to an optical path $\Delta \varphi=\frac{2 \pi . \delta n . e}{\lambda}$ equals to $n \pi$ (where $n \in N$ ); therefore the sensitivity is improved for a reflecting cell where the optical path is twice the liquid crystal thickness.

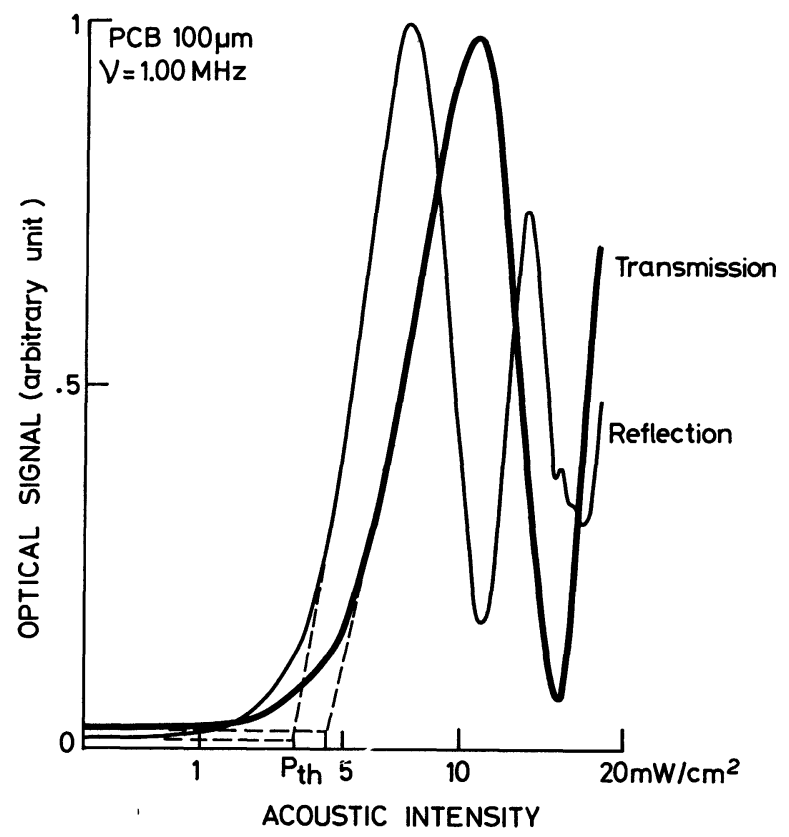

Fig. 4. - Variation of the optical signal at the centre of the irradiated area versus the acoustic intensity.

The dependence of the optical signal versus the thickness $d$ of the liquid crystal has been investigated. We observe that the sensitivity is roughly proportional to $d$.

This phenomena which has been observed by Dion, cannot be explained by his theoretical model. Recent observations has shown that this theory does not explain the observed features [9].

These behaviors, which are important for display applications, do not agree with previous theories $[2,4,5,7]$.

4. Display applications. - For display applications we have succeeded to increase the sensitivity and to reduce the response times by means of an electric field. On the other hand, the resolution has been also improved by means of a grid.

4.1 RESPONSE TIMES AND SENSITIVITY IMPROVEMENT. - The response times and the sensitivity were 
improved by applying an electric field on a nematic crystal whose dielectric anisotropy depends on the frequency of the applied electric field.

For this kind of compound the dielectric anisotropy is negative for a frequency $\mathrm{r}$ ' of the electric field greater than a critical frequency $v_{\mathrm{c}}$, and positive for a frequency lower than $v_{\mathrm{c}}$. As the initial alignment is homeotropic, for frequencies $v>v_{c}$, the electric field enhances the action of the ultrasounds (e.g. it increases the sensitivity and reduces the rise time). So this electric field is applied during the writing time $\tau_{\mathrm{r}}$.

On the other hand, for frequencies $v<v_{\mathrm{c}}$ the electric field restores the homeotropic alignment, so it reduces the decay time. This electric field is applied during the erasure time $\tau_{\mathbf{d}}$.

So one obtains an image frequency of the detector which is $:\left(\tau_{r}+\tau_{d}\right)^{-1}$. We have used in this application the ZLI 518 from Merck for which $v_{\mathrm{c}}=10 \mathrm{kHz}$;

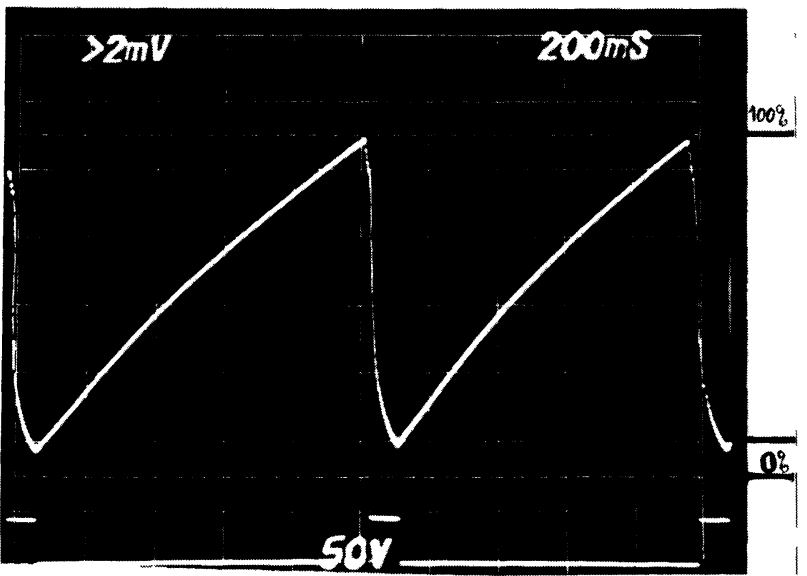

a)

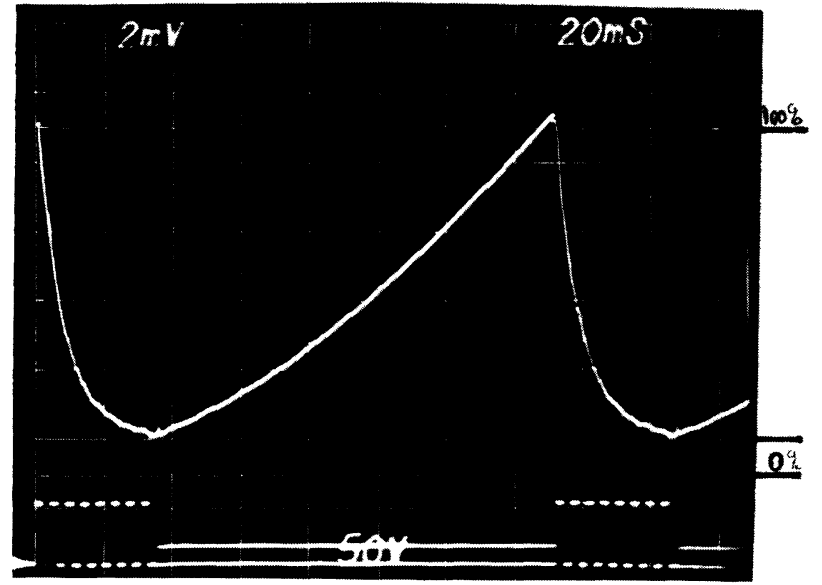

b)

Fig. 5. - Optical transmission versus time for a liquid crystal cell (ZLI 518) under ultrasonic irradiation with an applied electric field (lower curve). a) Image frequency : $1 \mathrm{~Hz} P_{\text {u.s. }}=5 \mathrm{~mW} / \mathrm{cm}^{2}$. b) Image frequency : $7 \mathrm{~Hz} P_{\text {u.s. }}=15 \mathrm{~mW} / \mathrm{cm}^{2}$. $\varepsilon_{\mathrm{a}}=+0.8$ for $v=200 \mathrm{~Hz} ; \varepsilon_{\mathrm{a}}=-0.4$ for $v=20 \mathrm{kHz}$ (measurements at $25^{\circ} \mathrm{C}$ ).

Figure 5 shows the optical transmission of this liquid crystal cell under ultrasonic irradiation; therefore the image frequency is increased to $1 \mathrm{~Hz}$ with on incident intensity of $5 \mathrm{~mW} / \mathrm{cm}^{2}$ or to $7 \mathrm{~Hz}$ with $15 \mathrm{~mW} / \mathrm{cm}^{2}$.

Hence, applying an electric field is a simple way to reduce the response time and to increase the sensitivity.

4.2 Resolution IMPROVEMENT. - On these cells ultrasonic images were not obtained because birefringence also occurred in the non irradiated regions of the cell. The new mechanism observed seems to extend to the whole cell and smears out the ultrasonic image. Taking into account this fact, we improved the resolution by introducting a grid in the cell thickness as suggested by Nagaï et al. [2, 8]. This grid which divides the sample into an array of liquid crystal domains restricts the action of the ultrasounds to each individual cell.

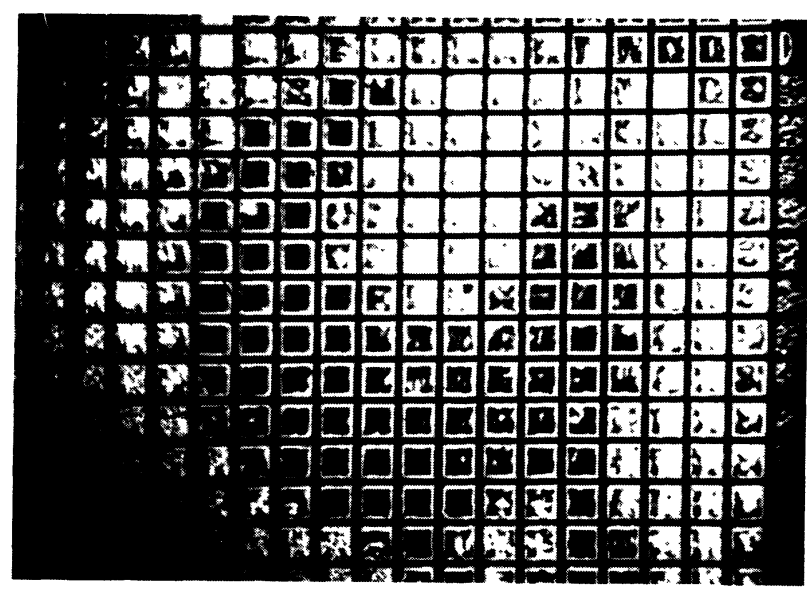

a)



b)

Fig. 6. - Direct image on the liquid crystal detector of the acoustic shadow of a key. Spacing period : $1 \mathrm{~mm}$. Frequency $v: 3.4 \mathrm{MHz}$. Acoustic intensity : $10 \mathrm{~mW} / \mathrm{cm}^{2}$. 
The birefringence observed (Fig. 4a) in these small cells gives direct acoustic images of objects placed between the cell and the transducer (Fig. $4 b$ ). Preliminary experiments show that the resolution of the cell is limited by the spacing period, other characteristics remained unchanged.

5. Conclusion. - This investigation has exhibited at least three different phenomena occurring at the same time in the liquid crystal cell, one of them being a mechanism which is not explained within the framework of previous models for the acousto-optic interaction. We have shown that it is possible to improve the resolution with a grid in the cell thickness and to get good response times with a medium sensitivity using an electric field.
Hence, we define a simple acoustic image detector giving a direct bidimensional image whose mean characteristics were :

- Ultrasound frequency : $1 \mathrm{MHz}$

$$
\begin{array}{ll}
\text { - Acoustic intensity } & : \text { about } 5 \mathrm{~mW} / \mathrm{cm}^{2} \\
\text { - Contrast ratio } & : 10 / 1 \\
\text { - Resolution } & : 1 \mathrm{~mm} \\
\text { - Frame rate } & : 1 \mathrm{~Hz} \\
\text { - Destabilizing voltage } & : 5 V_{\mathrm{rms}}(v=20 \mathrm{kHz}) \\
\text { - Erasing voltage } & : 40 V_{\mathrm{rms}}(v=200 \mathrm{kHz}) \text {. }
\end{array}
$$

Acknowledgments. - The authors wish to thank Mr. G. Gallet for technical assistance.

\section{References}

[1] Helfrich, W., Phys. Rev. Lett. 29 (1972) 1583.

[2] Nagaï, S., Peters, A., Candau, S., Revue Phys. Appl. 12 (1977) 21.

[3] Letcher, S., Lebrun, J., Candau, S., J. Acoust. Soc. Am. 63 (1978) 55.

[4] Miyano, K. and Shen, Y. R., Appl. Phys. Lett. 16 (1976) 281.
[5] Dion, J. L., C. R. Acord. Sci. B 284 (1977) 219.

[6] Dion, J. L. and Jacob, A. D., Appl. Phys. Lett. 31 (1978) 490.

[7] Sripaipan, C., Hayes, F., Fang. T.. Phys. Rev. A 15 (1977) 1297.

[8] Nagaï, S. and Iizuka, K., Japan. J. Appl. Phỵs. 17 (1978) 723.

[9] Perbet, J. N., To be published. 